\title{
Elite e legitimação na Faculdade de Direito do Vale do Paraíba
}

\author{
Elite and legitimation at the Vale do Paraíba Law School \\ Élite et légitimation à la Faculté de Droit du Vale do Paraíba
}

Elite y legitimación en la Facultad de Derecho del Vale do Paraíba

\author{
Maria Helena Alves da Silva ${ }^{1}$ \\ Maria Aparecida Chaves Ribeiro Papali ${ }^{1}$ \\ Antonio Carlos Machado Guimarães ${ }^{1}$
}

Recebido em 21/06/2017; revisado e aprovado em 08/11/2017; aceito em 14/11/2017

DOI: http://dx.doi.org/10.20435/inter.v0i0.1634

\begin{abstract}
Resumo: Este trabalho tem como objetivo discutir a criação da Faculdade de Direito no Vale do Paraíba em 1954, na cidade de São José dos Campos. Por meio de depoimentos de pessoas que viveram nesse período e publicações de jornais, foi possível concluir que a Faculdade foi criada como consequência da vontade da elite local de criar uma instituição de ensino privada que melhorasse a imagem da cidade e dos atores locais.

Palavras-chave: São José dos Campos; elite local; Faculdade de Direito.

Abstract: This work aims to discuss the creation of the Faculty of Law in the Vale do Paraíba in 1954, in the city of São José dos Campos. Through testimony from people who lived in this period and newspaper publications, it was possible to conclude that the Faculty was created as a consequence of the will of the local elite to create a private educational institution that would improve the image of the city and the local actors.

Keywords: São José dos Campos; local elite; Faculty of Law.

Résumé: Ce travail vise à discuter la création de la Faculté de Droit du Vale do Paraíba en 1954, dans la ville de São José dos Campos. Grâce à des témoignages de personnes qui vivaient à cette époque et à des publications de journaux, il a été possible de conclure que la Faculté était née de la volonté de l'élite locale de créer un établissement d'enseignement privé qui améliorerait l'image de la ville et des acteurs locaux.

Mots-clés: São José dos Campos; élite locale; Faculté de Droit.

Resumen: Este trabajo tiene como objetivo discutir la creación de la Facultad de Derecho en el Vale do Paraíba en 1954, en la ciudad de São José dos Campos. Por medio de testimonios de personas que vivieron en ese período y publicaciones de periódicos, fue posible concluir que la Facultad fue creada como consecuencia de la voluntad de la élite local de crear una institución de enseñanza privada que mejorara la imagen de la ciudad y de los actores locales.
\end{abstract}

Palabras clave: São José dos Campos; elite local; Facultad de Derecho.

\section{INTRODUÇÃO}

Pela Lei Complementar 440/11 de 27, de abril de 2011, o edifício da Faculdade de Direito do Vale do Paraíba, pertencente à Universidade do Vale do Paraíba (Univap), foi tombado como patrimônio histórico da cidade de São José dos Campos pelo Conselho Municipal de Preservação do Patrimônio Histórico, Artístico e Cultural (Comphac). No mesmo ano, criou-se na Universidade o Centro de História \& Memória da Univap (CEHVAP), com o objetivo de gerir a documentação e reconstruir o processo histórico de criação dos cursos pertencentes a Univap. Um dos principais focos do CEHVAP são os cursos mais antigos, como o curso de Direito, autorizado pelo Decreto n. 34.8892 de outubro de 1954.

Desde o início do século 20, a cidade de São José dos Campos havia sido o destino de diversos doentes e profissionais da saúde para o tratamento de tuberculosos, que acabaram se estabelecendo e tendo grande influência na política da cidade. Essa influência de pessoas

\footnotetext{
${ }^{1}$ Universidade do Vale do Paraiba (UNIVAP), São José dos Campos, São Paulo, Brasil.
} 
de fora da cidade teria sido percebida durante o período senatorial, compreendido entre as décadas de 1920 - 1950, quando a instalação de sanatórios foi feita de forma estratégica para atrair imigrantes e investimentos para a cidade. Com boa formação, os médicos sanitaristas que vieram para a cidade acabaram ocupando, por décadas, posições de destaque, principalmente a de prefeito (BONDESAN, 1999). Como observou Altino Bondesan, advogado e historiador que chegou na cidade na primeira metade do século 20, os recém-chegados, além de ocuparem essas posições, também contribuíam com uma "cultura superior":

Foi demorada a transformação de São José, de uma cidadezinha dependente da lavoura em uma estância de cura. O pessoal da cidade a princípio teve um pouco de resistência a receber os doentes, mas percebeu que eles eram uma fonte de renda, que São José com a decadência do café e naturalmente de toda a lavoura, passou a depender também muito desses novos elementos que traziam à cidade com a sua doença, fortaleza econômica. [...] Além de tudo tinha uma cultura muito superior, em São José era comum pessoas que falavam alemão, falavam o inglês, o francês, e nós.. quer dizer, depois veio o CTA e trouxe professores dessas línguas e tal que São José teve um sempre culturalmente, acredito eu, superior a cada cidades do Vale. (BONDESAN, 1999).

Nesse período sanatorial, o crescimento das cidades estava associado às transformações de um país independente que procurava, por meio das relações econômicas e pela 'incorporação de doutrinas, valores e modo de vida' se inserir no modelo de capitalismo igual a de outros países (ZANETTI, 2012, p. 32). A relação de superioridade cultural com línguas estrangeiras, comentado pelo depoente, é uma evidência dessa tentativa de adoção de valores culturais internacionais.

Aliada a essa tentativa de inserção de valores na cidade, estava a importância da educação superior, vista como necessária para o desenvolvimentos das cidades e seus habitantes. Dessa forma, utilizando do jornal 'Correio Joseense', publicado na cidade entre 1927-1960, depoimentos e revisão bibliográfica, este trabalho tem como objetivo discutir a criação da Faculdade de Direito no Vale do Paraíba em 1954.

\section{DISCUSSÃO}

Durante o período pós-guerra, em que se iniciaram políticas de industrialização e desenvolvimento tecnológico, a cidade foi escolhida para a instalação de diversos setores industriais, tendo como destaque o Centro Técnico Aeronáutico (CTA) e o Instituto Tecnológico de Aeronáutica (ITA), que trouxeram diversos alunos e profissionais de diversas regiões do Brasil.

É neste período que emerge o posicionamento de que todos os países deveriam alcançar o almejado 'desenvolvimento' igual aos dos países ricos, com a valorização do modo de vida urbano, transferência tecnológica e industrialização, de forma que a modernização e a industrialização são confundidas com progresso social (KNOX; TRIGUEIRO, 2011, p. 3). Nesse período, o Brasil tinha como projeto básico, a construção de um parque industrial para entrar para o ranking das principais potências mundiais, e essas propostas eram compatíveis com o capital financeiro e produtivo internacional, que se dispuseram a participar instalando no Brasil filiais, as chamadas multinacionais, embora tudo tenha sido feito dentro de um "processo interno excludente" (ARAUJO, 2000, p. 87).

Para Lessa, São José dos Campos foi uma cidade feita a partir de "estímulos externos": primeiro com o período sanatorial, marcado pelas primeiras intervenções urbanas e nas políticas públicas da cidade - quando São José dos Campos se transformou em uma cidade local; depois, aliada a um 
processo de concentração de investimentos e centralização, com grande atuação no setor terciário, com instalação de serviços voltados aos doentes. Marcado por investimentos públicos e privados e de políticas públicas que transformaram a malha urbana da cidade com o estabelecimento de tuberculosos, surgiu uma nova divisão social e territorial do trabalho e com um processo de "descentralização dos problemas urbanos" de São Paulo. Logo em seguida, São José se transformou em um polo regional com o Estado Novo, emergindo projetos interdependentes e marcados pelo planejamento estatal: o projeto industrial, no setor secundário, com a presença de indústrias bélicas e transnacionais, e o projeto militar, com a construção do CTA e a proposta de formação de mão de obra qualificada e produção de tecnologia e do conhecimento (LESSA, 2004, p. 2-4).

Acredita-se, também, que a estrutura e a ideologia sanatorial teriam atuado como facilitadora para o período seguinte, com a instalação da Rodovia Presidente Dutra, o CTA (Centro Técnico Aeroespacial) e as indústrias que margearam a rodovia, valorizando a terra e modificando o eixo de crescimento urbano (VIANA; ELIAS, 2007, p. 1302).

Figura 1 - Fotografia vista aérea da cidade de São José dos Campos em 1956

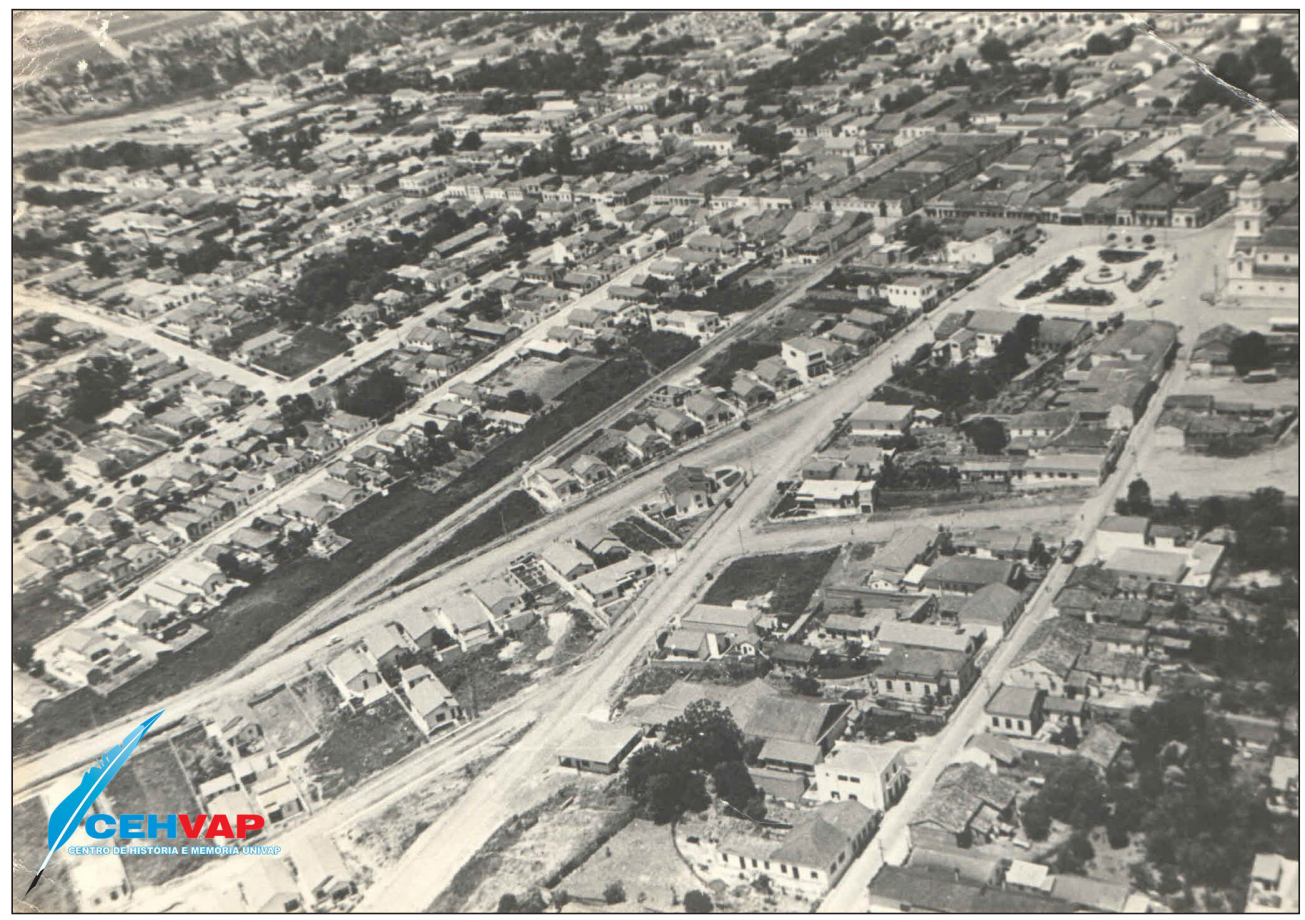

Fonte: Acervo do CEHVAP.

Analisando jornais das décadas entre 1940-1950 publicados na cidade de São José dos Campos, no interior de São Paulo, nota-se que o progresso é associado com a criação de escolas e faculdades. Na ocasião da criação da Faculdade de Farmácia e Odontologia em 1954, por exemplo, o jornal local 'Correio Joseense' noticiou que "como era natural", a notícia causou "grande contentamento à população que vê nessa escola superior mais um grande fator em favor da cidade que caminha a passos largos na conquista dos mais alevantados elementos de progresso", e que a cidade já se considerava a "vanguardeira" no que dizia respeito ao terreno educacional no Vale do Paraíba (CORREIO JOSEENSE, 1954, p. 7).

Criada pela Lei Estadual Paulista n. 2.631, de 20 de janeiro de 1954, a Faculdade de Farmácia e Odontologia foi iniciar suas atividades apenas seis anos depois de sua criação, em 28 de março 
de 1960. Uma outra Faculdade, com uma história bem diferente, foi criada no mesmo mês: a Faculdade de Direito do Vale do Paraíba. Enquanto a Faculdade de Farmácia e Odontologia teve como principal mentor o Deputado Feliciano, o curso de Direito foi criado a partir dos esforços de pelo menos seis pessoas: Everardo de Miranda Passos e Domingos de Custódio, dirigentes da Sociedade Civil Mantenedora; o aluno Jamil Mattar de Oliveira, que cursava Direito em São Paulo; Flávio Berling Macedo, José Vieira de Macedo e Luiz de Azevedo Castro. Uma vez que grande parte desses homens já tinham espaço na vida política da cidade e do Estado, é possível que a Faculdade de Direito tenha acontecido em um espaço tão curto de tempo por conta da influência de seus 'fundadores'.

De acordo com o jornal 'Correio Joseense', todos tinham alguma participação no cotidiano da cidade, fosse como professores ou promotores públicos, sendo considerados parte da "elite" ou, pelo menos, elementos de grande representatividade no coditiano joseense. Como observou Flávio M. Heinz em seu estudo sobre as elites, não há consenso sobre o que se entende por elite, quem são e o que a caracteriza: emprega-se esse termo em um sentido amplo para referenciar grupos ou categorias que parecem ocupar "estruturas de autoridade ou de distribuição de recursos", entendendo por esta palavra os dirigentes, pessoas influentes ou 'privilegiados'. Assim, essa noção de elite vem de uma percepção de atores que têm condições desiguais em relações a outros indivíduos no que se refere ao desempenho dos papéis políticos e sociais (HEINZ, 2006, p. 7).

A prática do Direito tem sido considerada uma linguagem-chave na questão da legitimação, cujos bacharéis eram intermediários internacionais do conhecimento técnico estatal, serviam como intermediários entre empresas e grandes famílias, agindo como estadistas, facilitando reformas sociais e promovendo a estabilidade dos chamados 'establishments'; no Brasil, o Direito têm desempenhado o papel central na legitimação e reprodução no Estado que implica a legitimação e reprodução de hierarquias sociais, ligando assim as famílias de maior destaque das oligarquias locais às Faculdades de Direito (DELAZAY; GARTH, 2000, p. 166).

Figura 2 - Foto da Faculdade de Direito do Vale do Paraíba, entre as décadas de 1960-1970

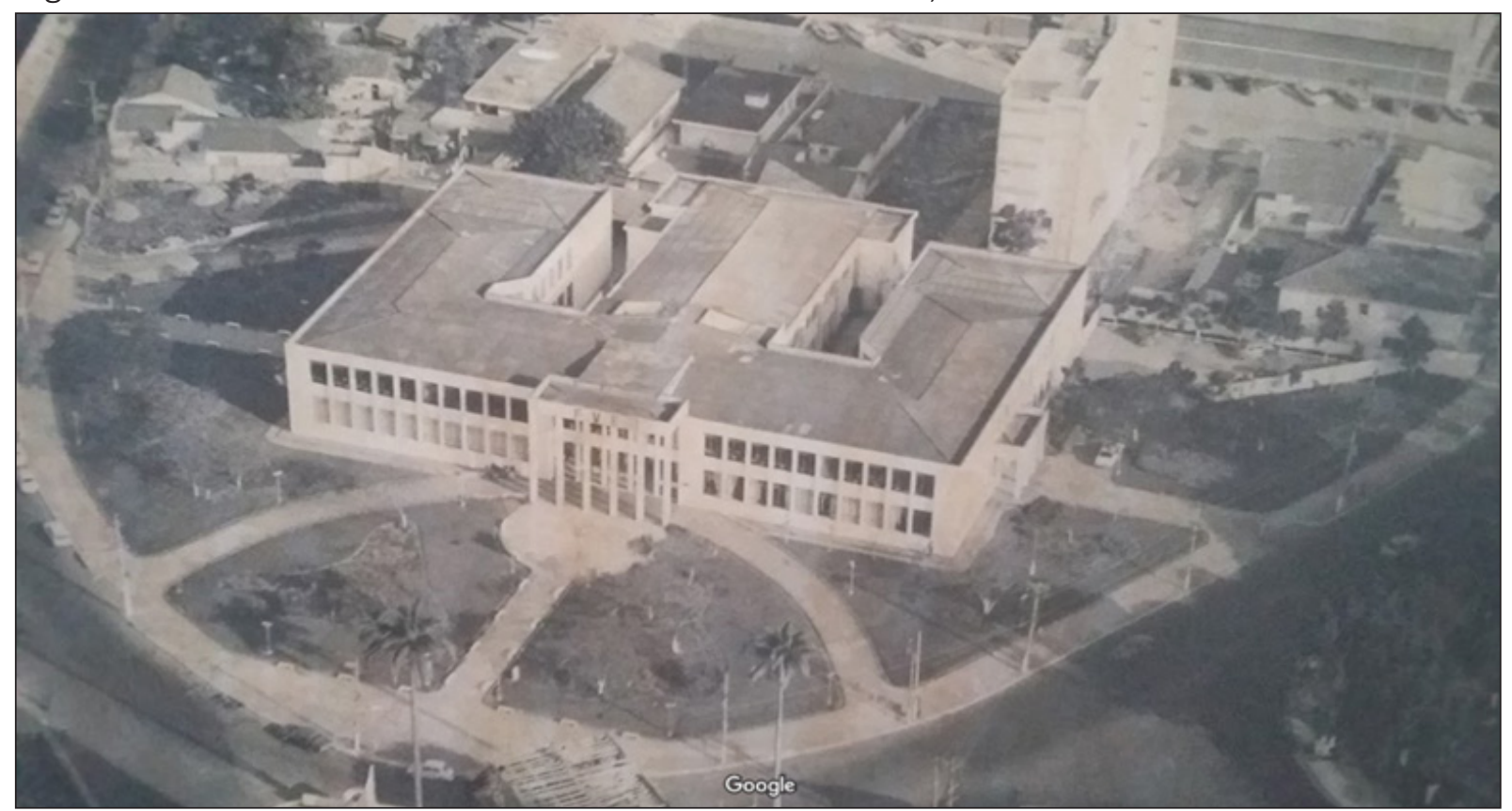

Fonte: Dias (2016). 
Além disso, o Direito também era visto como necessário para a formação de uma nova cultura no Brasil. Essa afirmação pode ser confirmada por meio da declaração de Franco Montoro (19161999), jurista e político, que disse ao jornal ValeParaibano que era dever do Poder Público auxiliar as entidades que defendiam e projetavam sua cultura para todo o Estado de São Paulo, e que, ao ensinar Direito para a juventude, elevar-se-ia a cultura de todo o Brasil. No mesmo depoimento, Montoro conta que a Faculdade de Direito era necessária para que o crescimento do Brasil não fosse marcado apenas "pela técnica, pela máquina, pelo progresso nacional, mas também por um progresso de cultura", para uma formação voltada para a justiça (BRASIL, 1957, p. 28).

Mas por qual motivo seria criada uma Faculdade de Direito em uma cidade que até pouco tempo era conhecida por seus sanatórios e indústrias de cerâmica e tecido? Desde o início do século 20, a cidade passou a ser o destino de diversos doentes e profissionais da saúde para o tratamento de tuberculosos, que acabaram se estabelecendo e tendo grande influência na política da cidade. Logo depois, durante o período pós-guerra, em que se iniciaram políticas de industrialização e desenvolvimento tecnológico, a cidade de São José dos Campos foi escolhida para a instalação de diversos setores industriais, tendo como destaque o CTA e o ITA, que trouxeram diversos alunos e profissionais de diversas regiões do Brasil. Combinados, esses três períodos nos mostram que, durante sua existência, a cidade de São José dos Campos sempre foi influenciada pelos outsiders, utilizando o termo de Nobert Elias e John Scotson (2000), que aqui chegaram com um objetivo - tratar da tuberculose ou trabalhar no setor industrial - mas que, por terem mais formação técnica e superior do que os próprios moradores da cidade, entraram na política local.

Essa influência de pessoas de fora da cidade teria sido percebida durante o período senatorial, compreendido entre as décadas de 1920-1950, quando a instalação de sanatórios foi feita de forma estratégica para atrair imigrantes e investimentos para a cidade. Com boa formação, os médicos sanitaristas que vieram para a cidade acabaram ocupando, por décadas, posições de destaque na cidade, principalmente a de prefeito (QUEIROZ, 2008, p. 63). Isso passou a ser um incômodo para os moradores - viver sobre a tutela do Estado. Em 1955, em uma publicação no jornal Correio Joseense, Stelio Machado Loureiro questionou a forma com que era feita a escolha dos prefeitos- que já era criticada pelos jornais locais:

Como pode um governo escolher prefeitos? Apoiado em que critério? Escolherá por ventura médicos sanitaristas ou engenheiros, que antes realizem estágios nesta Capital? Seguirá critérios de natureza política? Quando não pertence aos quadros de nenhum partido político, como é bem o caso atual, politicamente como resolverá o problema? Que autoridade sustenta a escolha de um prefeito por um governador que conhece as estâncias de passagem, durante a sua passagem por esses municípios em uma campanha eleitoral? Quem conhecerá melhor os homens que podem ser distinguidos para a chefia local do que os próprios moradores das estâncias? [...] Ninguém explica a exceção mantida no caso das Prefeituras Sanitárias. É verdade que tais municípios recebem do Estado um auxílio equivalente à sua arrecadação anual. O auxílio basta, porem, para que o Estado submeta politicamente o município que ajuda? (CORREIO JOSEENSE, 1955).

Seria três anos depois, em 1955, que a cidade teria a licença para escolher seus próprios prefeitos. No entanto a liberdade duraria pouco: seis anos depois, com a instauração do regime militar, a cidade teria novamente prefeitos nomeados (QUEIROZ, 2008, p. 63).

A ideia de um processo interno excludente teve, como pudemos observar, grande impacto na sociedade joseense desde o estabelecimento de doentes no período sanatorial, que 
acabaram por se tornar atores centrais na organização e na política da cidade, assim como os recém-chegados do ITA e o CTA. Dessa forma, notamos que os que se estabeleceram posteriormente, se articulavam mais facilmente e tinham mais prestígio nas esferas de deliberação e poder, enquanto os estabelecidos se viam em grande parte excluídos dos processos decisórios.

Por meio de depoimentos prestados ao projeto 'Patrimônio Humano' da Fundação Cultural Cassiano Ricardo, feitos na década de 1990 e hoje disponíveis para consulta no Pró-Memória São José dos Campos, foi possível entender melhor a dinâmica conflitiva entre esses dois grupos que se formaram: uma vez que o CTA tinha em seu campus todos os elementos que compunham uma cidade - uma capela, supermercado, restaurantes, hotel etc - os alunos e funcionários raramente saíam de lá. Quando saíam para a cidade, geralmente nos finais de semana, era para frequentar os mercados e as diversões que a cidade oferecia. Nesses momentos, havia conflito entre os jovens alunos do ITA e os jovens da cidade, uma vez que as moças se sentiam mais atraídas pelos novos moradores. Além disso, constatou-se que o mercado passou a ter dois preços diferenciados: um para os joseenses e outro, mais caro, para os recém-chegados.

Dessa forma, é possível ponderar que a instalação da Faculdade de Direito se vincula a uma mudança no contexto local ocorrido pela relação entre os antigos moradores e os novos habitantes, motivados pela acelerada industrialização do município naquele momento. Podemos então entender a criação de uma Faculdade como forma de legitimação da elite na forma de um investimento no campo do conhecimento. De acordo com Sposito, quando uma elite é confrontada por uma nova escala, ela pode criar formas de se reafirmar, com a criação de instrumentos industriais ou escolas (SPOSITO, 2007, p. 246).

A criação de uma Faculdade reforçava um perfil diferenciado de uma cidade, dando prestígio a suas elites. Como observou Adilson Avansi de Abreu, em seu estudo sobre a estruturação do território paulista e a USP, desde o 2ำ Reinado as elites de São Paulo aplicavam seus recursos financeiros na modernização urbana, indústria e na malha ferroviária, seguindo "padrões europeizados, compreendendo progressivamente com mais clareza o papel da ciência, tecnologia e educação no processo de desenvolvimento e estruturação do território" (ABREU, 2004, p. 11). Para o autor, a criação da uma instituição de ensino ocorre quando há uma "convergência que une a liderança intelectual com a política" (ABREU, 2004, p. 11-2).

É possível notar por meio do jornal local 'Correio Joseense' que a criação de faculdades era vista como parte do conceito de 'progresso', fosse ele científico, cultural ou industrial, de forma a evidenciar que o conhecimento científico era necessário para o desenvolvimento da cidade. Por exemplo, no ano de 1954, o redator do jornal, Napoleção Monteiro, acreditava que a cidade necessitava de um deputado na Assembléia legislativa, e foi colocado na matéria tudo que se considerava de valor na cidade:

São José dos Campos, a cidade das Indústrias, do comércio sempre crescente, da pecuária, da lavoura, e futura cidade universitária, já possuindo Faculdade de Direito, em funcionamento, de Engenharia no Centro Técnico de Aeronáutica, e de Farmácia e Odontologia a funcionar no próximo ano, contando com Colégio Estadual e Escola Normal e milhares de estudantes, tem o direito de possuir o seu Deputado Estadual. (CORREIO JOSEENSE, 1954 , p. 35).

Como observou Maurici Damasceno, historiador e advogado, quanto ao tombamento do edifício da Faculdade de Direito em 2010, o edifício da Faculdade se tornou um símbolo da luta de São José dos Campos a favor de sua história com suas próprias Faculdades, e não apenas com a do ITA: compreendido por sua importância, o ITA foi uma escola "do Brasil", mas a cidade 
não poderia "perder as suas raízes ou vê-las apagadas por outra"; assim, a Faculdade de Direito é "um marco na vida do povo de São José, e o seu prédio é uma referência da luta dos mestres e da juventude por sua criação" (DAMASCENO, 2010).

\section{CONSIDERAÇÕES FINAIS}

A chegada de novos moradores na cidade - com a instalação do período sanatorial e do período industrial - fez com que novas pessoas fizessem parte do cotidiano da cidade e de sua vida política. O fato de elas terem chegado em um momento crítico de urbanização da cidade (fruto do investimento ocorrido durante a fase sanatorial), junto de outras empresas atraídas pela acelerada industrialização no município, fez com que as estruturas urbanas locais fossem sobrepostas por lógicas de poder fora do alcance da política e da economia local, fazendo com que os atores nacionais tivessem mais influência do que os locais.

Uma forma que os moradores da cidade encontraram de destacar a política de seu município e, assim, se legitimar perante esses novos moradores, foi a criação de um novo espaço com essa finalidade. Tendo como exemplo Faculdades de Direito que fizeram com que suas cidades se tornassem símbolos de desenvolvimento cultural e urbano, assim como espaços de sociabilidade e educação, a Faculdade de Direito do Vale do Paraíba foi criada, permitindo que, em poucas décadas, seus alunos pudessem fazer parte de secretarias e prefeituras da cidade.

\section{REFERÊNCIAS}

ABREU, Adilson Avansi de. A USP e a estruturação do território paulista. In: PRADO, Maria Lígia Coelho (Org.). Cidades universitárias: patrimônio urbanístico e arquitetônico da USP. São Paulo: EdUSP, 2004.

ARAUJO, Tania Bacelar de. A experiência de planejamento regional no Brasil. In: LEVINAS, Lena; CARLEIAL, Liana Maria da Frota; NABUCO, Maria Regina (Org.). Reestruturação do espaço urbano e regional no Brasil. São Paulo: Hucitec, 2000.

BONDESAN, Altino. Depoimento cedido à TV UNIVAP em um documentário sobre tuberculose, feito em 1999. Disponível em DVD no Centro de História e Memória (CEHVAP) da UNIVAP.

BRASIL. Projeto de Lei n. 3234/1957. Concede a subvenção anual de cr\$5.000.000,00 a Faculdade de Direito do Vale do Paraiba, no estado de São Paulo. Brasília-DF, 1957. Disponível em: http://www.camara. gov.br/proposicoesWeb/fichadetramitacao?idProposicao=210857. Acesso em: 22 jun. 2017.

CORREIO JOSEENSE. 1955. Disponível em: http://www.camarasjc.sp.gov.br/promemoria/wp-content/ uploads/2016/01/1955.pdf. Acesso em: 13 jun. 2019.

CORREIO JOSEENSE. 1954. Disponível em: http://www.camarasjc.sp.gov.br/promemoria/wp-content/ uploads/2016/01/1954.pdf. Acesso e

DAMASCENO, Maurici. Sobre a Faculdade de Direito. Publicado em 10 de novembro de 2010. Disponível em: http://mauricix.blog.uol.com.br/arch2010-11-07_2010-11-13.html\#2010_11-10_13_52_49-2519180-0. Acesso em: 28 nov. 2016.

DELAZAY, Yves; GARTH, Bryant. A dolarização do conhecimento técnico profissional e do Estado: processos transnacionais e questões de legitimação na transformação do Estado, 1960-2000. RBCS - Revista Brasileira de Ciências Sociais, v. 15, n. 43, p. 163-76, jun. 2000. 
DIAS, Nilceira. Visão aérea da Faculdade de Direito, entre 1960 e 1980. Contribuição enviada para o Google Maps em abril de 2016. Disponível em: https://goo.gl/maps/eBzp5BNGLys. Acesso em: 11 nov. 2016. ELIAS, Norbert; SCOTSON, John L. Os estabelecidos e os outsiders. Rio de Janeiro: Zahar, 2000.

HEINZ, Flávio M. Por outra história das elites. Rio de Janeiro: FGV, 2006.

KNOX, Winifred; TRIGUEIRO, Aline. Quando o desenvolvimento do outsider atropela o envolvimento dos insiders: um estudo de campo de desenvolvimento no litoral do ES. In: CIRCUITO DE DEBATES ACADÊMICOS, 1., 2011. Brasília: IPEA Code, 2011. Disponível em: https://www.researchgate.net/publication/274715065_ Quando_o_desenvolvimento_outsiders_atropela_o_envolvimento_dos_insiders. Acesso em: 22 nov. 2016.

LESSA, Simone Narciso. São José dos Campos: O planejamento e a construção do pólo regional do Vale do Paraíba. In: SEMINÁRIO DE HISTÓRIA DA CIDADE E DO URBANISMO, 8., 2004. Anais [...]. Disponível em: https://www.anpuhsp.org.br/sp/downloads/CD\%20XVII/ST\%20II/Simone\%20Narciso\%20Lessa.pdf. Acesso em: 22 nov. 2016.

QUEIROZ, Alberto V. Com a palavra, o prefeito- perfis e depoimentos dos políticos que governaram São José dos Campos na segunda metade do século 20. São José dos Campos, SP: Prefeitura Municipal de São José dos Campos, 2008.

SPOSITO, Maria Encarnação Beltrão. Cidades médias: reestruturação das cidades e reestruturação urbana. In: SPOSITO, Maria Encarnação Beltrão (Org.). Cidades médias: espaços em transição. São Paulo: Expressão Popular, 2007.

VIANA, Paula Carnevale; ELIAS, Paulo Eduardo. Cidade sanatorial, cidade industrial: espaço urbano e política de saúde em São José dos Campos, São Paulo, Brasil. Cadernos de Saúde Pública, Rio de Janeiro, v. 23, n. 6, p. 1295-308, jun. 2007. Disponível em: http://www.scielo.br/pdf/csp/v23n6/04.pdf. Acesso em: 13 nov. 2016.

ZANETTI, Valéria. Cidade e identidade: São José dos Campos, do peito e dos ares. São Paulo: Annablume/ FAPESP, 2012.

\section{Sobre Autores:}

Maria Helena Alves da Silva: Graduada em História, mestranda em Planejamento Urbano e Regional pela UNIVAP. Gestora de documentos no Centro de História e Memória da Univap (CEHVAP). E-mail: maria.42246@yahoo.com.br, Orcid: http://orcid.org/0000-0002-4796-2595

Maria Aparecida Chaves Ribeiro Papali: Doutora em História Social e Mestre em História do Brasil pela Pontifícia Universidade Católica de São Paulo (PUC-SP). Graduada em História pela Universidade do Vale do Paraíba. Professora na Universidade do Vale do Paraíba, atuando na Graduação (Cursos de História e Geografia) e na Pós-Graduação, como docente permanente do Mestrado em Planejamento Urbano e Regional, na Linha de Pesquisa "Sociedade, Espaço e Cultura". Coordenadora do Núcleo de Pesquisa "Pro-Memória São José dos Campos" e do Laboratório de Pesquisa e Documentação Histórica (IP\&D/UNIVAP). E-mail: papali@univap.br, Orcid: http://orcid.org/0000-0002-8234-4266

Antonio Carlos Machado Guimarães: Doutor em Ciências Sociais pela Pontifícia Universidade Católica de São Paulo (PUC-SP). Mestre em Antropologia Social e Bacharel em Ciências Sociais pela Universidade Estadual de Campinas (UNICAMP). Colaborador do Programa de Pósgraduação em Planejamento Urbano e Regional da Universidade do Vale do Paraíba. E-mail: ac.guimaraens@gmail.com, Orcid: http://orcid.org/0000-0002-7144-1378 